\title{
Mapeamento de mosquitos Aedes spp. e detecção do vírus Dengue em zona urbana do município de Picos, Piaú
}

\author{
Mapping the distribution of Aedes spp. and Dengue virus detection in the urban area of the \\ municipality Picos, Piauí
}

Mapeo del mosquitos Aedes spp. y detección del virus del Dengue en zona urbana del municipio de Picos, Piauí

José Cleves da Silva Maia ORCID: https://orcid.org/0000-0003-0934-235X Universidade Federal do Piauí, Brasil E-mail: cleves09@outlook.com

Henrique Rafael Pontes Ferreira ORCID: https://orcid.org/0000-0002-7444-2085 Universidade Federal de Pernambuco, Brasil E-mail: henrique.pontes@ufpe.br

Lucas Emanuel Sousa e Silva ORCID: https://orcid.org/0000-0001-7765-0907 Universidade Federal do Piauí, Brasil

E-mail: prof_lucasemanuel@ hotmail.com

Jailson da Silva Santana

ORCID: https://orcid.org/0000-0003-2762-1045 Universidade Federal do Piauí, Brasil E-mail: jailsonsej@gmail.com

José Fabrício de Carvalho Leal ORCID: https://orcid.org/0000-0003-1402-2545 Universidade Federal do Piauí, Brasil E-mail: fabriciobrycio15@gmail.com Alexandre da Costa Teixeira ORCID: https://orcid.org/0000-0002-5773-5628 Universidade Federal do Piauí, Brasil

E-mail: alexandreteixeira51@ hotmail.com

Agda Paolla Siqueira Fontes da Silva ORCID: https://orcid.org/0000-0002-9101-6686 Universidade Federal do Piauí, Brasil

E-mail: agdapao@gmail.com

Isadora da Silva Moura

ORCID: https://orcid.org/0000-0001-9794-7134 Universidade Federal do Piaú, Brasil E-mail: isadoramoura15@hotmail.com

Arnaldo Solheiro Bezerra

ORCID: https://orcid.org/0000-0001-7912-7394 Rede Nordeste de Biotecnologia - RENORBIO, Brasil

Universidade Estadual do Ceará, Brasil

E-mail: abezerra14@gmail.com

Bruno Bezerra Silva

ORCID: https://orcid.org/0000-0002-9881-201X Universidade Estadual do Ceará, Brasil E-mail: bezerra.biomol@gmail.com

Victor Emanuel Pessoa Martins ORCID: https://orcid.org/0000-0002-6254-7971 Universidade da Integração Internacional da Lusofonia Afro-Brasileira, Brasil E-mail: victormartins@unilab.edu.br

Maria Izabel Florindo Guedes ORCID: https://orcid.org/0000-0002-4569-8663 Universidade Estadual do Ceará, Brasil E-mail: florinfg@uol.com

Marcia Maria Mendes Marques ORCID: https://orcid.org/0000-0001-7661-2570 Universidade Federal do Piauí, Brasil E-mail: marciammm2003@ufpi.edu.br 
Ana Carolina Landim Pacheco

ORCID: https://orcid.org/0000-0002-2237-9133

Universidade Federal do Piaú, Brasil

E-mail: carolandim@ufpi.edu.br

\begin{abstract}
Resumo
Objetivo: mapear a distribuição de mosquitos Aedes spp. em zona urbana do município de Picos, Piauí, associando a variáveis climáticas e identificar os sorotipos circulantes do virus Dengue em Aedes aegypti. Métodos: foram instaladas 30 armadilhas do tipo larvitrampas em 10 bairros da zona urbana do município. As larvas foram coletadas, semanalmente, no período de fevereiro de 2017 a julho de 2019, e encaminhadas para o laboratório onde foram identificadas e contadas. O número de larvas foi associado a dados meterológicos. Após as larvas atigirem a fase adulta, os mosquito A. aegypti foram segregados em pools com 6 exemplares e submetidos a RT-PCR e Nested-PCR para detecção do sorotipo DENV. Resultados: um total de 44.798 larvas de Aedes spp foram coletadas em área urbana de Picos durante o período de estudo. $\mathrm{O}$ aumento das chuvas e diminuição da temperatura, principalmente nos meses de fevereiro e março, contribuiram para o aumento da infestação desses vetores no mês de abril. No estudo, foi coletado duas larvas de Haemagogus spegazzinii, potencial vetor de febre amarela. A maior ocorrência no município foi da espécie A. aegypti (96,43\%), presente em todos bairros estudados, com predominancia em ambiente intradomicíliar, enquanto o A. albopictus (3,57\%) ocupa ambiente peridomicíliar. As análises moleculares de $A$. aegypti apresentaram positividade para o vírus DENV 1 e DENV 3, demonstrando a existência de transmissão transovariana. Conclusão: Esse estudo demonstrou a ocorrência concomitante de A. aegypti e A. albopictus em zona urbana e a co-circulação dos sorotipos 1 e 3 da dengue. $O$ monitoramento entomológico e da circulação viral são importantes ferramentas para indicar áreas de maior infestação de mosquitos vetores e prevenir futuros surtos, fornecendo subsídios para o planejamento de ações voltadas ao controle e a prevenção de arboviroses , através da secretária de saúde e órgãos competentes na região.
\end{abstract}

Palavras-chave: Arbovírus; Área urbana; Controle vetorial; Reação em Cadeia da Polimerase; Vírus da Dengue.

\begin{abstract}
Objective: mapping of the distribution of Aedes spp. in the urban area of the municipality of Picos, Piauí associating the climate variables and identification the dengue virus serotypes circulating in Aedes aegypti mosquito populations. Methods: Thirty larvitraps were installed in 10 neighborhoods in the urban area of the municipality. Larvae were collected weekly during the period from February 2017 to July 2019, and the collected material was taken to laboratory for identification and counting. The number of larvae were associated with meteorological data. In adult stage, the A. aegypti mosquitoes were segregated into pools containing six specimens and were then subjected to RTPCR and Nested-PCR assay for detection of the DENV serotype. Results: a total of 44,798 Aedes spp. larvae were collected in the urban area of Picos during study period. An increase in precipitation and decrease in temperature in the months of February and March contributed to the increase in infestation of these vectors in April. In the study, two larvae of Haemagogus spegazzinii, a potential vector of yellow fever, were collected. The highest occurrence in the municipality was of the species A. aegypti (96.43\%) present in all neighborhoods studied with predominance in domiciliary environment, while A. albopictus (3.57\%) occur in the peridomiciliary environment. Molecular analyzes of the A. aegypti were positive for DENV 1 and DENV 3 viruses, demonstrating the existence of transovarial transmission. Conclusion: This study showed the simultaneous occurrence of A. aegypti and A. albopictus in the urban area and the co-circulation of dengue serotypes 1 and 3. Entomological and viral circulation monitoring are important tools to indicate areas of greater infestation of vector mosquitoes and prevent future outbreaks, providing results for the actions aimed at the control and prevention of arboviruses, through the secretary of health and competent bodies in the region.
\end{abstract}

Keywords: Arbovirus; Urban area; Vector Control; Polymerase Chain Reaction; Dengue virus.

\title{
Resumen
}

Objetivo: mapear la distribución de Aedes spp. bajo la influencia de factores climáticos en una zona urbana del municipio de Picos, Piauí e identificar los serotipos circulantes del virus del Dengue en Aedes aegypti. Métodos: 30 larvitrampas fueron instaladas en 10 barrios del área urbana del municipio. Se colectaron larvas (febrero 2017 a julio 2019) semanalmente, se identificaron, contaron y simultáneamente se tomaron datos meteorológicos. Los mosquitos adultos A. aegypti fueron segregaron en grupos con 6 especímenes y se sometieron a RT-PCR y Nested-PCR para la detección del serotipo DENV. Resultados: se recolectaron un total de 44.798 larvas de Aedes spp en área urbana de Picos. El aumento de las precipitaciones y la disminución de la temperatura en el municipio, principalmente entre diciembre y abril, provocaron un incremento en la infestación de estos mosquitos. En el estudio se recogieron dos larvas de Haemagogus spegazzinii, potencial vector de la fiebre amarilla. La mayor ocurrencia en el municipio fue de la especie A. aegypti (96,43\%), presente en todos los barrios estudiados, con predominio en el ambiente interior, mientras que A. albopictus (3,57\%) ocupa el ambiente peridomiciliar. Los análisis moleculares de A. aegypti mostraron positividad para los virus DENV 1 y DENV 3, demostrando la existencia de transmisión transovárica. Conclusión: Este estudio demostró la presencia concomitante de A. aegypti y A. albopictus en áreas urbanas y la 
circulación conjunta de los serotipos 1 y 3 del dengue. Lo controle entomológicos y de circulación viral son herramientas importantes para señalar áreas de mayor infestación de mosquitos vectores y prevenir futuros brotes, subsidiando acciones encaminadas al control y prevención de arbovirus, a través de la Secretaría de Salud y organismos competentes en la región.

Palabras clave: Arbovirus; Área urbana; Control de Vectores; Reacción en Cadena de la Polimerasa; Virus del Dengue.

\section{Introdução}

Arboviroses (Arthropod-borne virus) como a dengue, chikungunya, zika e febre amarela constituem um sério problema de saúde pública em muitos países do mundo, transmitidas ao homem pelos mosquitos Aedes aegypti (Linnaeus, 1762) e Aedes albopictus (Skuse, 1894) (Gould et al., 2017). O risco de contrair doenças transmitidas por esses vetores vem aumentando em conjunto com mudanças na distribuição e adaptação desses insetos a ambientes urbanos, impulsionada pelos deslocamentos, migrações, ocupação de áreas e transportes humanos e pela presença de condições climáticas e socioeconômicas favoráveis para o desenvolvimento dos mosquitos (Kraemer et al., 2019). Fatores abióticos como a temperatura, humidade, vento e precipitação são determinantes na manutenção destas espécies. Estas variáveis climáticas podem afetar a oviposição, a viabilidade-ovo, o desenvolvimento larvar, a longevidade e a dispersão dos adultos (Moura et al., 2020).

No Brasil, o A. aegypti é o principal vetor de arbovírus e o A. albopictus é considerado transmissor potencial (Heinisch et al., 2019). A espécie A. aegypti é essencialmente urbana com comportamento antropofílico e endofílico, encontrada predominantemente dentro das residências. Utiliza recipientes artificiais como locais preferenciais de oviposição, a exemplo de: pneus descartados, garrafas, caixas d'água, latas e vasos de plantas (Silva et al., 2018). O A. albopictus está bem adaptado aos habitats preservados, fragmentos florestais e áreas rurais (Oliveira \& Neto, 2017), embora sua presença tenha sido relatada em ambiente urbano, coabitando os mesmos criadouros de A. aegypti (Martins et al., 2010).

A dengue é considerada uma das arboviroses de maior importância global. O Brasil enfrenta epidemias de dengue desde 1986, sazonalmente de março a junho. Em meio a pandemia do novo coronavírus (SARS-CoV-2) o país registra casos de dengue e covid-19 simultaneamente (Mascarenhas et al., 2020). A principal forma de transmissão da dengue para humanos ocorre através da picada da fêmea de mosquito infectado durante o repasto sanguíneo. A transmissão transovariana ou transmissão vertical também é relatada, ocorrendo quando a fêmea transmite o vírus Dengue (DENV) para sua prole e essa forma de transmissão é considerada um fator decisivo na persistência do vírus em meio urbano (Martins et al., 2012; Silva et al., 2018; Zeidler et al., 2008). Desde 2010, os quatro sorotipos: DENV-1, DENV-2, DENV-3 e DENV-4 são encontrados em circulação no Brasil (Zanotto \& Leite, 2018; Rabelo et al., 2020).

A integração das ações da vigilância entomológica e detecção viral são necessárias, a fim de fornecer aporte para métodos de controle e prevenção das arboviroses (Camara 2016). Considerando essa importância e a falta de intervenções dessa natureza na região, o presente estudo teve como objetivo mapear a distribuição de mosquitos Aedes spp. sob influência de fatores climáticos e identificar os sorotipos circulantes do vírus Dengue em zona urbana do município de Picos, Piauí.

\section{Metodologia}

\section{1 Área de estudo}

A pesquisa foi realizada no município de Picos, localizado na região do semiárido do Piauí, centro Sul do estado com

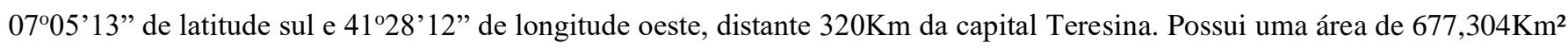
com uma população estimada de aproximadamente 78.627 mil habitantes, clima tropical, semiárido quente e seco com 
temperaturas médias que chegam a $34^{\circ} \mathrm{C}$, com duas estações bem definidas (seca e chuvosa) (Aguiar \& Gomes, 2004; IBGE, 2021).

\subsection{Coleta dos dados meterológicos}

Dados meteorológicos (temperatura e pluviometria) utilizados neste trabalho foram provenientes da estação meteorológica de Picos, PI (Código OMM 82780) (INMET, 2020).

\subsection{Armadilhas larvitrampas}

Armadilhas do tipo larvitrampa foram confeccionadas de pneu com $40 \mathrm{~cm}$ de comprimento, $8 \mathrm{~cm}$ de largura e $28 \mathrm{~cm}$ de circunferência. Foram instaladas a uma altura aproximada de 1,60m do solo (Figura 1) em locias sombreados com distância média entre as armadilhas de 300 metros (Silva et al., 2009).

Figura 1. Armadilha larvitrampa confeccionada de pneu (a): $40 \mathrm{~cm}$ de comprimento, (b): $8 \mathrm{~cm}$ de largura, (c): $28 \mathrm{~cm}$ de circunferência e (d): local de instalação.

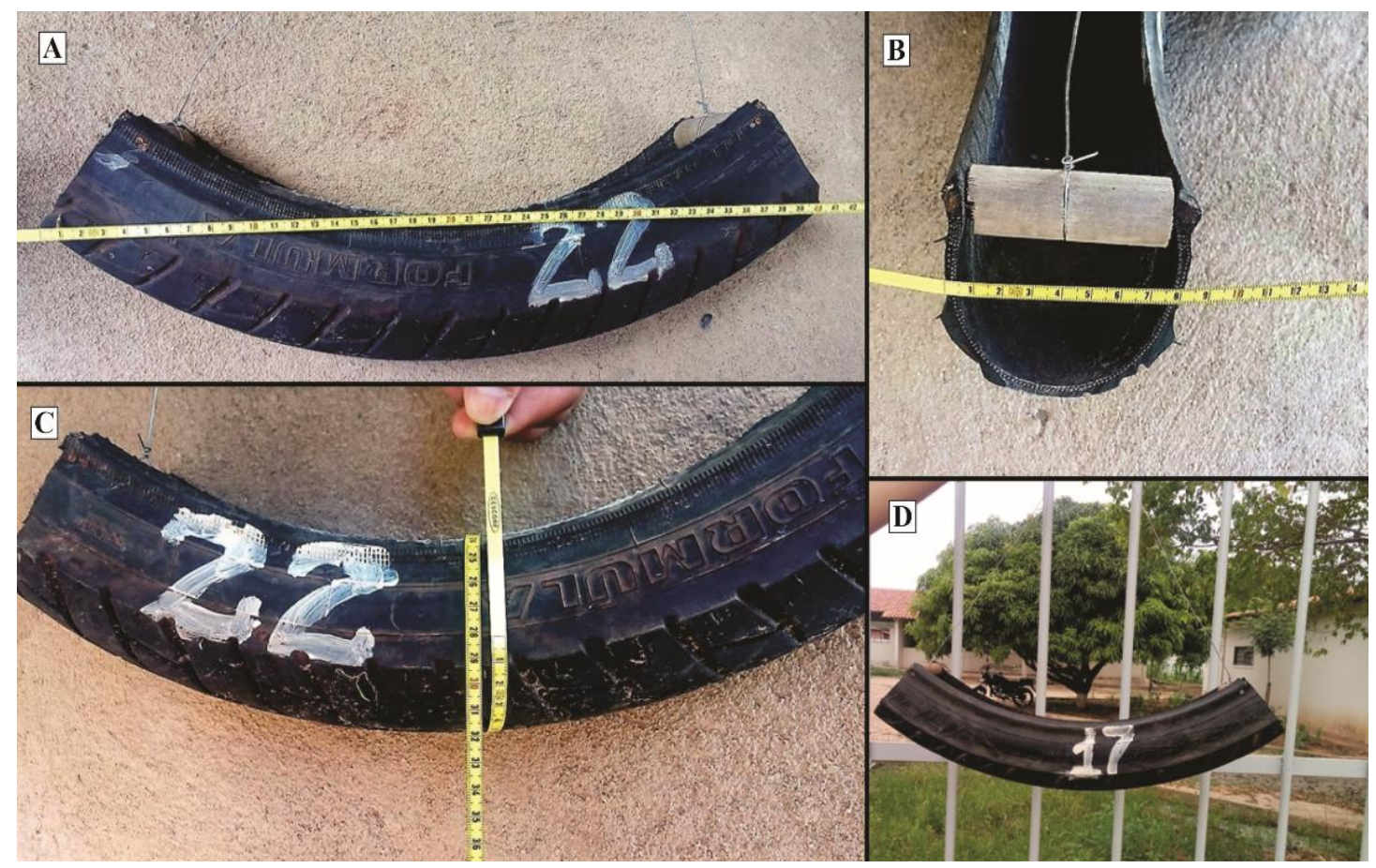

Fonte: Dados da pesquisa (2019).

Foram usados três locais de instalação das armadilhas: ambiente intradomiciliar, peridomiciliar e extradomiciliar, distribuídas em 10 bairros da área urbana da cidade. A escolha dos bairros se deu em consonância com o Centro de Controle de Zoonoses (CCZ) do município e usou como critério de inclusão bairros com alta densidade populacional e aglomerados de residências, condições propícias para proliferação dos vetores. Foi elaborado um mapa de Picos com a localização das 30 armadilhas larvitrampas instaladas nos bairros usando software QGIS 3.22.00 (Figura 2A).

\subsection{Coleta de formas imaturas, manutenção e identificação}

Formas imaturas (larvas) foram coletadas de fevereiro de 2017 a julho de 2019, semanalmente. As amostras foram acondicionadas em tubos de plástico de $50 \mathrm{~mL}$, contendo água do próprio criadouro, devidamente identificados quanto a localização (bairro) e, posteriormente, eram encaminhadas para o Laboratório de Parasitologia Ecologia e Doenças 
Negligenciadas (LAPEDONE) da Universidade Federal do Piauí, Campus Senador Helvídio Nunes de Barros UFPI/CSHNB. Após a coleta, as armadilhas eram lavadas e a água substituída.

No LAPEDONE, as larvas eram mantidas em recipientes de plástico contendo $400 \mathrm{~mL}$ de água com alimentação para triagem a nivel de gênero (Forattini, 2002). Ao atingirem o estágio de pupa, eram transferidas para recipientes de plástico de $50 \mathrm{~mL}$, adaptados para a manutenção das formas adultas (Martins et al., 2010). Após atigirem a forma alada, os mosquitos adultos foram contabilizados e mantidos em temperatura de $4^{\circ} \mathrm{C}$, em freezer, durante 5 minutos, para anestesia-los e facilitar sua identificação com chave de identificação (Forattini, 2002). A mortalidade de larvas criadas em condições laboratoriais foi uma das principais limitações do estudo.

\subsection{Extração do RNA viral (RT-PCR e Nested-PCR)}

Para a detecção do vírus Dengue foi utilizado mosquitos fêmeas de A. aegypti, provenientes da coleta do mês de abril de 2017. Foram agrupados em pools de até 6 exemplares e armazenados a $-80^{\circ} \mathrm{C}$. Todos os pools foram macerados a seco em microtubos $(2,0 \mathrm{~mL})$, com o auxílio de bastões de vidro $(1,0 \mathrm{~cm}$ x $30 \mathrm{~cm})$. Submetidos à extração de RNA viral, utilizando-se para isso o QIAmp Viral RNA® mini kit (Qiagen®), seguindo-se as instruções do fabricante.

A amplificação e a detecção de segmento específico do genoma dos vírus Dengue foram realizadas a partir das reações de RT-PCR seguido de uma nested-PCR, a qual visa à identificação dos sorotipos do vírus mediante o uso de consensus primers (D1 e D2) e primers reverse tipo-específicos (type-specific primers) para cada sorotipo (TS1, TS2, TS3 e TS4) (Tabela 1). Para tanto, 100 ng do RNA viral extraído foi, em uma única reação, convertido a DNA complementar e amplificado com os primers D1 e D2 com a seguinte programação: 1) transcrição reversa (30 minutos a $\left.50^{\circ} \mathrm{C}\right)$; ativação da PCR $\left(15\right.$ minutos a $\left.95^{\circ} \mathrm{C}\right)$; amplificação $\left(30\right.$ segundos a $94^{\circ} \mathrm{C} ; 60$ segundos a $55^{\circ} \mathrm{C} ; 2$ minutos a $\left.72^{\circ} \mathrm{C}\right)$ por 35 ciclos. Para a caracterização do sorotipo viral, o produto da primeira amplificação foi diluído 100x e usado como amostra para uma nested PCR utilizando agora os primers TS1, TS2, TS3 e TS4 com a mesma programação de amplificação, mas agora para apenas 20 ciclos. Amostra previamente isolada e caracterizada de DENV 1 foi utilizada como controle positivo, enquanto que água destilada foi empregada como controle negativo para as reações (Lanciotti, et al., 1992).

Os produtos oriundos da nested PCR foram analisados por meio de eletroforese em gel de agarose a 1,5\%, utilizando como referencial o marcador molecular 1 kb plus DNA ladder (Invitrogen $®)$. A detecção dos segmentos amplificados ocorreu em transiluminador ultravioleta (Biosystems ${ }^{\circledR}$ ) após o gel ser corado com o intercalante Sybr Safe (Invitrogen®), segundo as orientações do fabricante.

Tabela 1. Primers (oligonucleotídeos iniciadores) utilizados nas reações de RT-PCR/nested-PCR para sorotipagem do vírus dengue em pools de mosquitos coletados no município de Picos, PI.

\begin{tabular}{|c|c|c|c|}
\hline Primers & Sequência & $\begin{array}{c}\text { Posição de } \\
\text { hibridização } \\
\text { no genoma }\end{array}$ & $\begin{array}{c}\text { Tamanho do } \\
\text { amplicon (pb) }\end{array}$ \\
\hline D1 & 5'-TCAATATGCTGAAACGCGCGAGAAACCG-3' & $134-161$ & \multirow{2}{*}{$511(\mathrm{D} 1+\mathrm{D} 2)$} \\
\hline D2 & 5'-TTGCACCAACAGT-CAATGTCTTCAGGTTC-3' & $616-644$ & \\
\hline TS1 & 5'CGTCTCAGTGATCCGGGGG3' & $568-586$ & 482 (D1+TS1) \\
\hline TS2 & 5'CGCCA-CAAGGGCCATGAACAG3' & $232-252$ & 119 (D1+TS2) \\
\hline TS3 & 5'TAACATCATCATGA-GACAGAGC3' & $400-421$ & $290(\mathrm{D} 1+\mathrm{TS} 3)$ \\
\hline TS4 & 5'CTCTGTTGTCTTAAACAAGAGA3' & $506-527$ & 392 (D1+TS4) \\
\hline
\end{tabular}

Fonte: Martins et al. (2012). 


\section{Resultados}

Um total de 44.798 larvas de Aedes spp. foram coletadas com armadilhas larvitrampas instaladas em área urbana do município de Picos (Figura 2A) no período de 2017 a 2019. No ano de 2017, foram coletadas 3.831 larvas, com posterior aumento nos anos seguintes, 16.803 em 2018 e 24.164 em 2019.

O A. aegypti foi coletado em todos os 10 bairros amostrados sendo o mosquito vetor mais predominante na cidade, enquanto A. albopictus ocorreu em sete bairros. Foi possível identificar nas coletas, pela primeira vez, a presença de Haemagogus spegazzinii Brethes, 1912 (Diptera, Culicidae) no bairro Paraibinha. O espécime foi coletado, em uma armadilha localizada no bairro Paraibinha, co-circulando com Aedes (Figura 2B).

Figura 2. (A) Localização das larvitrampas e (B) presença de Aedes aegypti, Aedes albopictus e Haemagogus spegazzinii coletados em bairros da zona urbana do município de Picos, PI, entre fevereiro de 2017 a julho de 2019.

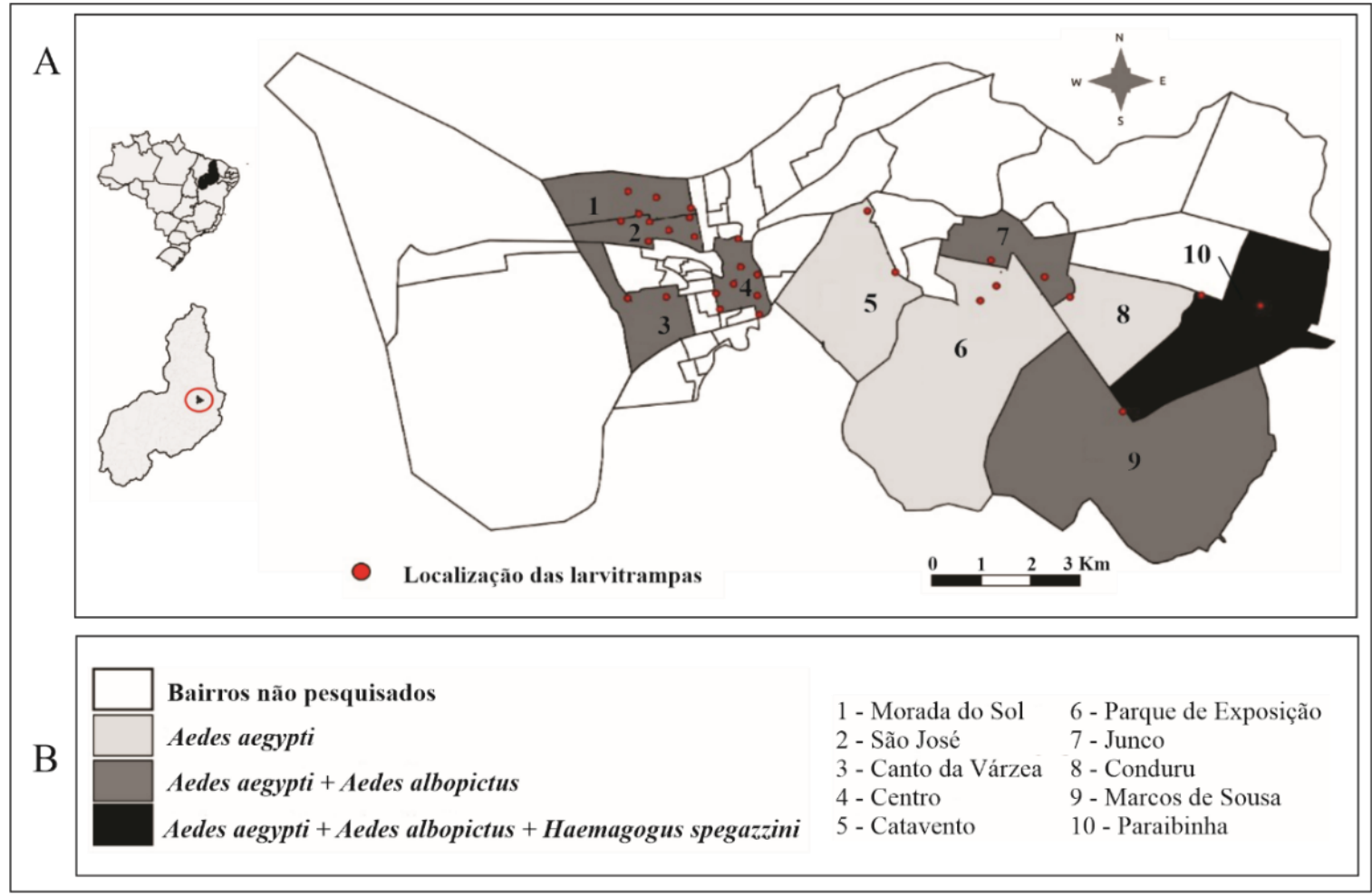

Fonte: Dados da pesquisa (2019).

Em relação a coleta de larvas de Aedes spp. por bairro, o maior quantitativo de larvas coletadas foi no bairro São José com registro de 15.792 (35,26\%) seguido do bairro Junco com 9.338 larvas (20,84\%) e Morada do Sol com 6.940 (15,49\%). O bairro Catavento foi o que apresentou o menor número de larvas $91(0,2 \%)$ (Figura 3). 
Figura 3. Número de larvas Aedes spp. por bairros coletadas por meio de larvitrampa no município de Picos, PI, Brasil, no período de fevereiro de 2017 a julho de 2019.

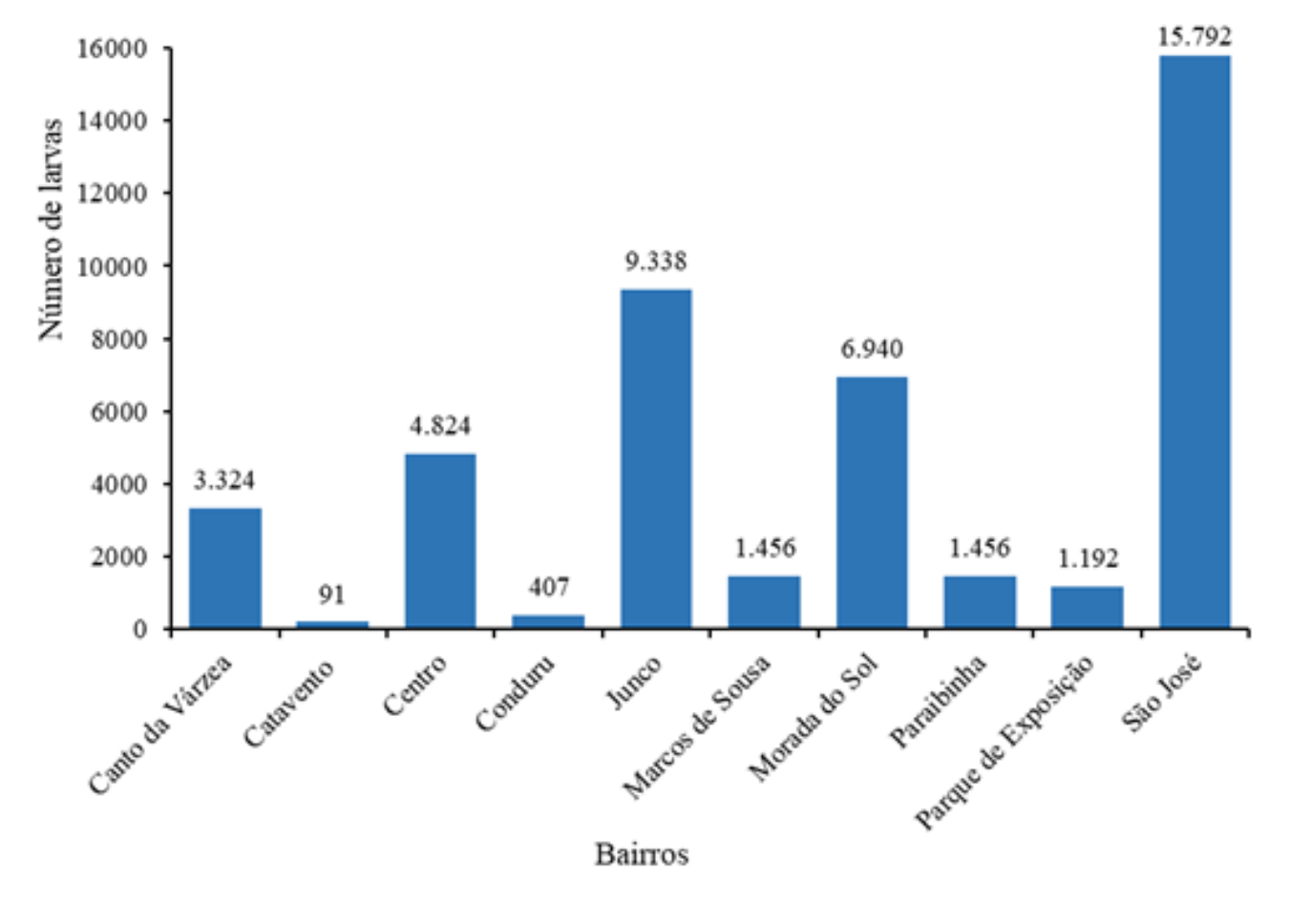

Fonte: Dados da pesquisa (2019).

O número de larvas Aedes spp. foi analisado de acordo com o mês de coleta. Os resultados demonstraram que o mês de abril se configurou como o pico das coletas, em todos os anos amostrados. Analisando o mês de pico, o ano de 2017 apresentou o menor registro do mosquito, menos de mil exemplares. Esse cenário foi muito diferente nos anos seguintes, em 2018 e 2019 o mês de abril apresentou uma alta na ocorrência de mosquitos de 6 a 8 vezes maiores, respectivamente (Figura $4 \mathrm{~A})$.

Em todo o período de estudo, os meses de fevereiro e março foram os que registraram os maiores índices de precipitação e com temperaturas variando entre 26 a $28^{\circ} \mathrm{C}$ (Figura 4B), o que contribuiu para o aumento da coleta de larvas de Aedes spp. no mês de abril (Figura 4A). Houve um aumento na infestação dos vetores logo após o aumento das chuvas e diminuição da temperatura no município. 
Figura 4. (A) Número de larvas de Aedes spp. coletados com larvitrampas e (B) Precipitação Total e Temperatura média de acordo com os meses, de fevereiro de 2017 a julho de 2019 no município de Picos, PI, Brasil.

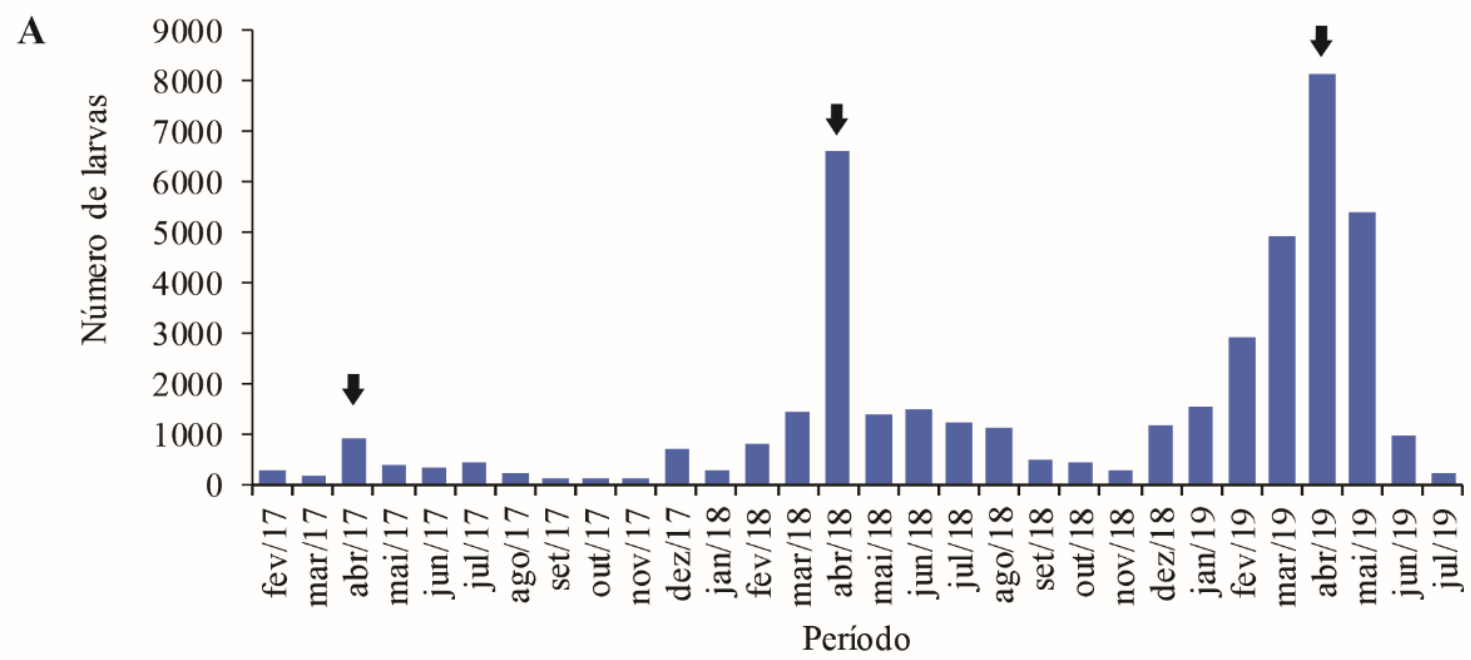

- Formas imaturas

B

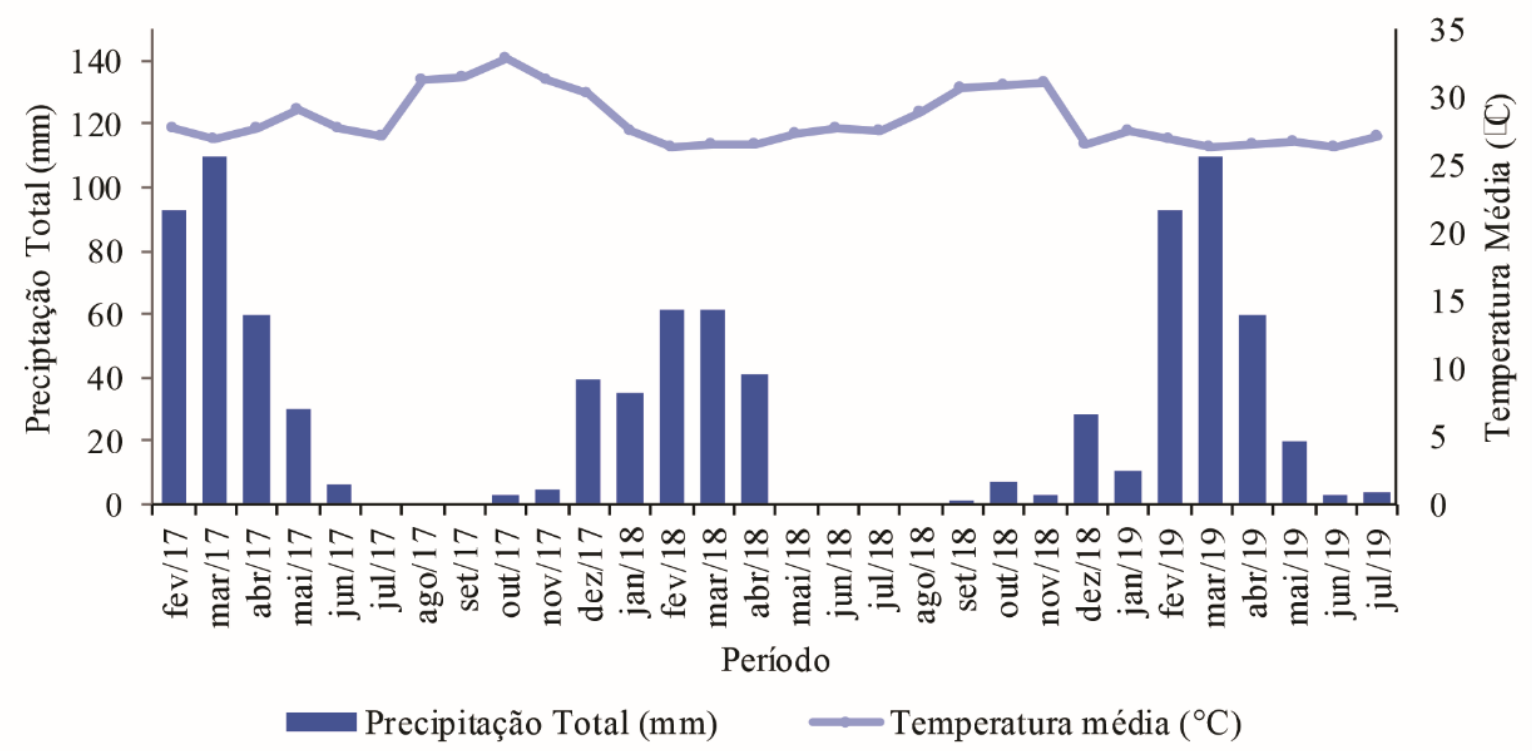

Fonte: Dados da pesquisa (2019).

As espécies A. aegypti e A. albopictus foram encontradas em ambiente peri, intra e extradomiciliar, com maior número de A. aegypti no intradomicílio (56,85\%) e A. albopictus no peridomicílio (58,52\%) (Tabela 2). Resultados que indicam a adaptação de Aedes spp. em ambientes urbanos. 
Tabela 2. Aedes aegypti e Aedes albopictus em ambientes intradomiciliar, peridomiciliar e extradomiciliar no município de Picos, PI, no período de fevereiro de 2017 a julho de 2019, de acordo com o ponto de localização da larvitrampa.

\begin{tabular}{rcc}
\hline Espécie/Localização & $\mathbf{N}$ & $\mathbf{\%}$ \\
\hline Aedes aegypti & $\mathbf{1 7 . 2 4 1}$ & $\mathbf{9 6 , 4 3}$ \\
Intradomicílio & 9.802 & 56,85 \\
Peridomicílio & 7.360 & 42,69 \\
Extradomicílio & 79 & 0,46 \\
\hline Aedes albopictus & $\mathbf{6 3 9}$ & $\mathbf{3 , 5 7}$ \\
Intradomicílio & 226 & 35,36 \\
Peridomicílio & 372 & 58,22 \\
Extradomicílio & 41 & 6,42 \\
\hline Total & $\mathbf{1 7 . 8 8 0}$ & $\mathbf{1 0 0}$ \\
\hline
\end{tabular}

Fonte: Dados da pesquisa (2019).

Diante da maior ocorrência de A. aegypti no municipio de Picos foi realizado um diagnóstico da detecção do DENV em amostras do mosquito. Dentre as amostras analisadas, foram identificados três pools positivos para o vírus Dengue. sendo que todos foram positivos para DENV 1 e um pool foi positivo tanto para DENV 1 quanto para DENV 3. Os produtos amplificados foram analisados em gel de agarose 1,5\%, corado com brometo de etídio a $1 \%$ (Figura 5). No poço 2,3 e 4 a banda de 482 pares de bases correspode ao DENV 1; no poço 2 a banda de aproximadamente 290 pares de base ao DENV 3. Resultados que demonstram a existência do mosquito A. aegypti naturalmente infectados com DENV no município de Picos.

Figura 5. Detecção do DENV em amostras de mosquitos Aedes aegypti coletados no município de Picos-PI. Poços: (1) marcador molecular 1 kb, (2) DENV 1 e 3, (3) DENV 1, (4) controle positivo DENV 1 e (5) controle negativo.

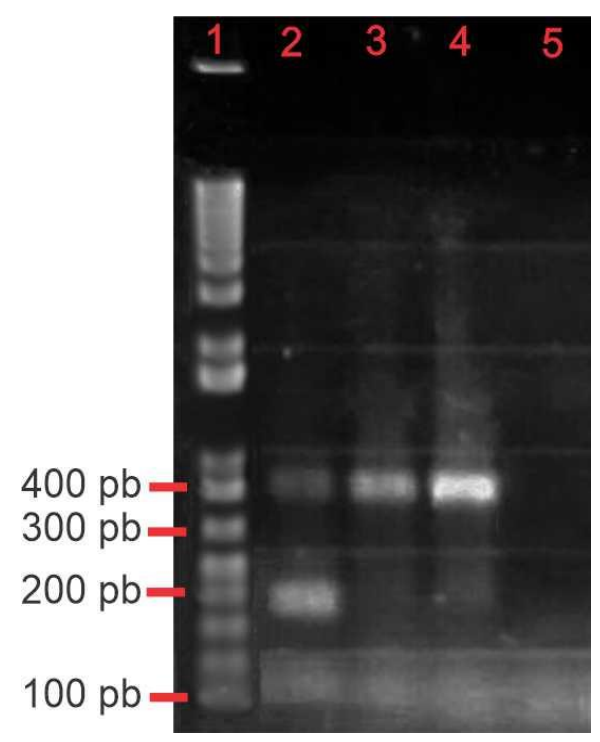

Fonte: Dados da pesquisa (2019). 


\section{Discussão}

Através da instalação de armadilhas larvitrampas em bairros da área urbana no município de Picos foi possível verificar a presença de A. aegypti e A. albopictus, mosquitos vetores de arboviroses (Figura 2 e 3). A presença desses mosquitos nos bairros pode ser associado a condições para sua permanência: acúmulo de lixo nas ruas, esgoto a céu aberto, grande quantidade de reservatórios de água como caixas d'água e baldes, devido a frequente falta de água em alguns bairros, contribuindo para o aumento de criadouros e, consequente, proliferação de formas imaturas do mosquito (Kraemer et al., 2019).

Ademais, neste estudo foi coletado dois espécimes do mosquito H. Spegazzinii um macho e uma fêmea co-circulando com Aedes (Figura 2). Os criadouros preferenciais desta espécie são buracos em árvores ou internódios de bambus e os mosquitos adultos ficam ativos, preferencialmente, nas copas de árvores densas, onde exercem hematofagismo no período diurno (Mangudo et al., 2018). Este foi o primeiro registro da espécie H. spegazzinii em área urbana de caatinga estrita, além disso, é importante ressaltar o fato excepcional de que os espécimes estavam em ambiente artificial e zona urbana, demonstrando a capacidade de adaptação deste culicídeo a ambientes que diferem de seu habitat silvestre. A presença da espécie na região é um alerta aos órgãos de vigilância entomológica, pois esse culicídeo é considerado um potencial vetor da febre amarela silvestre (Cano et al., 2021).

A maior ocorrência de Aedes spp. foi no mês de abril em todos anos investigados, considerado o pico de coleta (Figura 4A), Correlacionando com os casos de dengue ocorridos em Picos, o maior número de casos no ano de 2017, por exemplo, foi registrado em meses posteriores ao pico de coleta de larvas de Aedes com 50 e 83 casos nos meses de maio e junho, respectivamente, 10 vezes mais elevado que meses anteriores (Brasil, 2021). Resultados que demonstram quanto maior a infestação do mosquito, maior potencial de risco de transmissão de dengue.

O mês de abril também é o de maior pluviosidade (Figura 4B). Com o aumento da pluviosidade e a diminuição na temperatura, a proliferação de A. aegypti é favorecida pelo aumento da disponibilidade de criadouros propícios para oviposição da fêmea (Heinisch et al., 2019). Nos períodos de aumento de temperatura e escassez de chuvas, o desenvolvimento dos vetores fica comprometido, é quando os ovos podem entram em diapausa à espera de períodos com ocorrência de chuvas em que as larvas eclodem (Garzón et al., 2021).

As espécies A. aegypti e A. albopictus foram encontradas em ambiente peri, intra e extradomiciliar na cidade (Tabela 2). O A. aegypti foi coletado majoritariamente em condições intradomiciliar, resultado esperado visto a sua bem-sucedida adaptação à hematofagia quase exclusiva em humanos e sua fácil colonização (Moura et al., 2020). O mosquito A. albopictus foi coletado principalmente no peridomicílio. Esta espécie é comum em ambiente silvestre e rural, depositando seus ovos em criadouros naturais, mas também é capaz de colonizar criadouros artificiais em meio urbano, estabelecendo assim uma competição com o A. aegypti (Martins et al., 2013).

Este estudo também é inédito na deteç̧ão do vírus Dengue em mosquitos para a região centro-sul do Piauí e demonstrou a circulação de DENV 1 e 3 em Picos no ano de 2017. Mosquitos fêmeas de A. aegypti adultos coletados em zona urbana estavam naturalmente infectados, demonstrando também a transmissão transovariana do DENV, visto a utilização de exemplares adultos recém emergidos privados de qualquer fonte de alimentação sanguínea. Essa forma de transmissão é considerada um fator decisivo na persistência do vírus em meio urbano (Forattini \& Brito, 2003; Zeidler et al., 2008).

Adoção de medidas de controle de mosquitos Aedes no municipio de Picos é fundamental para conter possíveis surtos de arboviroses. Na cidade encontra-se um dos principais entroncamentos rodoviários da região Nordeste do Brasil, cortado pela BR-316 (ou rodovia Transamazônica), BR-407 e BR-230, ficando muito próxima a BR-020, que interliga os estados do Piauí ao Maranhão, Ceará, Pernambuco e Bahia, além das rodovias estaduais PI-236, PI-238, PI-375 e PI-379 (Viana et al., 
2017) e torna a cidade vulnerável a doenças transmitidas por mosquitos, uma vez que, vetores infectados podem ser transportados pela malha rodoviária para o município ou deste para as cidades vizinhas.

\section{Conclusão}

Os mosquitos A. aegypti e A. albopictus se encontram distribuidos em área urbana do município de Picos-Piauí, com maior ocorrência do A. aegypti em ambientes intradomiciliar e A. albopictus em ambiente intradomiciliar. Fatores climáticos, especialmente a chuva e temperatura, influenciaram o aumento da infestação desses mosquitos no mês de abril, considerado o mês de pico em todos os anos amostrados na pesquisa. Foi confirmado a circulação dos sorotipos Dengue 1 e 3 em mosquitos A. aegypti naturalmente infectados, comprovando a transmissão transovariana. O monitoramento entomológico e da circulação viral são importantes ferramentas para indicar áreas de maior infestação de mosquitos vetores e prevenir futuros surtos, fornecendo subsídios para o planejamento de ações voltadas ao controle e a prevenção de arboviroses , através da secretária de saúde e órgãos competentes da região.

\section{Agradecimentos}

Ao Centro de Controle de Zoonoses (CCZ) da Prefeitura Municipal de Picos, pelo apoio à pesquisa

\section{Referências}

Aguiar, R., \& Gomes, J. (2004). Projeto cadastro de fontes de abastecimento por água subterrânea, estado do Piauí. CRPM. Retrieved from: http://rigeo.cprm.gov.br/jspui/bitstream/doc/16506/1/Rel_SantaCruzdosMilagres.pdf

Brasil. (2013). Ministério da Saúde. Secretaria de Vigilância em Saúde. Levantamento Rápido de Índices para Aedes aegypti - LIRAa - para vigilância entomológica do Aedes aegypti no Brasil. https://bvsms.saude.gov.br/bvs/publicacoes/manual_liraa_2013.pdf

Brasil. Fundação Nacional de Saúde. Ministério da Saúde. Dengue: Instruções para Pessoal de Combate ao Vetor e Manual de Normas Técnicas. (2001). Fundação Nacional de Saúde. Retrieved Dec 20, 2021, from http://www.saude.mppr.mp.br/arquivos/File/dengue/manual_de_normas_tecnicas_funasa.pdf

$\begin{array}{lllll}\text { Brasil. Ministério da Saúde. Informações de } & \text { Saúde } & \text { (DATASUS-TABNET). }\end{array}$ http://tabnet.datasus.gov.br/cgi/deftohtm.exe?sinannet/cnv/denguebpi.def

Cano, M., Marti, G., Balsalobre, A., et al. (2021). Database of Sabethes and Haemagogus (Diptera: Culicidae) in Argentina: Sylvatic Vectors of the Yellow Fever Virus. J Med Entomol, 58(4), 1762-1770. https://doi.org/10.1093/jme/tjab059

Costa, A., Santana, C., Silva, V. et al. (2016). Análise do controle vetorial da dengue no sertão piauiense entre 2007 e 2011. Cad Saude Publica, 24(3), 275285. https://doi.org/10.1590/1414-462×201600030035

Couto-Lima, D., Madec, Y., Bersot, M., et al. (2017). Potential risk of reemergence of urban transmission of Yellow Ferver virus in Brazil facilitated by competence Aedes populations. Scie Rep, 7(1), 1-12. http://dx.doi.org/10.1038/s41598-017-05186-3

Forattini, O. (2002). Culicidologia médica: Identificação, biologia e epidemiologia. Editora da Universidade de São Paulo.

Garzón, M., Maffey, L., Lizuain, A. et al. (2021). Temperature and photoperiod effects on dormancy status and life cycle parameters in Aedes albopictus and Aedes aegypti from subtropical Argentina. Med Vet Entomol. https://onlinelibrary.wiley.com/doi/epdf/10.1111/mve.12474

Gould, E., Pettersson, J., Higgs, S. et al. (2017). Emerging arboviruses: Why today? One Health, 4-11. https://doi.org/10.1016/j.onehlt.2017.06.001

Heinisch, M., Diaz-Quijano, F., Chiaravalloti-Neto, F. et al. (2019). Seasonal and spatial distribution of Aedes aegypti and Aedes albopictus in a municipal urban park in São Paulo, SP, Brazil. Acta Trop., 189, 104-113. https://doi.org/10.1016/j.actatropica.2018.09.011

Heinisch, M., Diaz-Quijano, F., Chiaravalloti-Neto, F., \& et al. (2019). Seasonal and spatial distribution of Aedes aegypti and Aedes albopictus in a municipal urban park in São Paulo, SP, Brazil. Acta Trop., 189, 104-113. https://doi.org/https://doi.org/10.1016/j.actatropica.2018.09.011

IBGE. Instituto Brasileiro de Geografia e Estatística. Cidades. (2021). Brasil. https://cidades.ibge.gov.br/brasil/pi/picos/panorama

INMET. Instituto Nacional de Meteorologia. Estações Convencionais http://www.inmet.gov.br/portal/index.php?r=home/page\&page=sobre_inmet

Kraemer, M., Reiner Jr, R. C., Brady, O. et al. (2019). Past and future spread of arboviruses vectors Aedes aegypti and Aedes albopictus. Nat Microbiol, 4, 854-863. https://doi.org/10.1038/s41564-019-0376-y

Lanciotti, R. S., Calisher, C. H., Gubler, D. J., Chang, G. J., \& Vorndam, A. V. (1992). Rapid detection and typing of dengue viruses from clinical samples by using reverse transcriptase-polymerase chain reaction. Journal of Clinical Microbiology, 30(3), 545-551. https://doi.org/10.1128/jcm.30.3.545-551.1992 
Research, Society and Development, v. 11, n. 1, e56311125157, 2022

(CC BY 4.0) | ISSN 2525-3409 | DOI: http://dx.doi.org/10.33448/rsd-v11i1.25157

Mangudo, C., Aparicio, J., Rossi, G. et al. (2018). Tree hole mosquito species composition and relative abundances differ between urban and adjacent forest habitats in northwestern Argentina. Bull Entomol Res, 108(2), 203-212. https://doi.org/10.1017/S0007485317000700

Martins, V., Alencar, C., Facó, P., et al. (2010). Distribuição espacial e características dos criadouros de Aedes albopictus e Aedes aegypti em Fortaleza, Estado do Ceará. Rev Soc Bras Med Trop, 43(1), 73-77. https://doi.org/10.1590/S0037-86822010000100016

Martins, V., Alencar, C., Kamimura, M., et al. (2012). Occurrence of Natural Vertical Transmission of Dengue-2 and Dengue-3 Viruses in Aedes aegypti and Aedes albopictus in Fortaleza, Ceará, Brazil. PLoS ONE, 7(7), 1-9. https://doi.org/10.1371/journal.pone.0041386

Moura, M., Oliveira, J., Pedreira, R., et al. (2020). Spatio-temporal dynamics of Aedes aegypti and Aedes albopictus oviposition in an urban area of northeastern Brazil. Trop Med Int Health, 25(12), 1510-1521. https://doi.org/10.1111/tmi.13491

Oliveira, V., \& Neto, L. (2017). Ocorrência de Aedes aegypti e Aedes albopictus em bromélias cultivadas no Jardim Botânico Municipal de Bauru, São Paulo, Brasil. Cad Saude Publica, 33(1), e00071016. https://doi.org/10.1590/0102-311x00071016

Silva, S., Silva, E., Amoretty, P., et al. (2018). Spacial Distribution of Dengue Vectors Aedes aegypti and A. albopictus (Diptera: Culicidae) in the city of Volta Redonda, state of Rio de Janeiro, Brazil. ReonFacema. https://www.facema.edu.br/ojs/index.php/ReOnFacema/article/view/421

Silva, V. C; Serra-Freire, N. M.; Silva, J. S; Scherer, P. O.; Rodrigues, I.; Cunha, S. P.; \& Alencar, J. (2009). Estudo comparativo entre larvitrampas e ovitrampas para avaliação da presença de Aedes aegypti (Diptera: Culicidae) em Campo Grande, Estado do Rio de Janeiro. Rev Soc Bras Med Trop, 42(6), 730-731. https://doi.org/10.1590/S0037-86822009000600023

Viana, A., Nunes, H., Silva, J., et al. (2017). Caracterização fisiográfica e socioeconômica do município de Picos/PI: potencialidades, limitações e vulnerabilidades. InterEspaço: R Geogr Interdiscip, 3(9), 88-108. http://dx.doi.org/10.18764/2446-6549.v3n9p88-108

Zanotto, P., \& Leite, L. (2018). The Challenges Imposed by Dengue, Zika, and Chikungunya to Brazil. Front Immunol, 9, 1964. https://doi.org/10.3389/fimmu.2018.01964

Zeidler, J., Acosta, P., Barreto, P., et al. (2008). Vírus Dengue em larvas de Aedes aegypti e sua dinâmica de infestação, Roraima, Brasil. Rev Saúde Pública, 42(6), 986-991. https://doi.org/10.1590/S0034-89102008005000055 